\title{
Simulation of the heat accumulator operation of the internal combustion engine preheating system
}

\author{
Klara Luniaka ${ }^{1}$, Serhii Rusanov ${ }^{2}$, Oleksandra Kliuieva ${ }^{2 *}$, and Oleh Kliuiev ${ }^{2}$ \\ ${ }^{1}$ Kherson Branch of the Admiral Makarov National University of Shipbuilding, Ushakova Ave, 44, Kherson, Ukraine \\ ${ }^{2}$ Kherson National Technical University, Beryslav Highway, 24, Kherson, Ukraine
}

\begin{abstract}
We considered the heat accumulator with a phase-transfer heat-accumulating material, which serves for pre-heating of the car's internal combustion engine. Simulation of the heat accumulator operation allows to build calculated graphs of temperature change of the heat-accumulating material in time, and afterwards to determine the charging time of the heat accumulator depending on its design features, thus, by modelling the most optimal design solution. We performed numerical computations of the system enginecirculating fluid - heat storage material - environment in two stages. In the first stage, we calculated the parameters of thermal resistance in the engine system and pipe manifold for different coolant temperatures according to the method of finite volume in the CFD system. In the second stage the problem was solved numerically by the method of equivalent thermal circuit. We carried out phase transition simulation using the Stefan condition, based on the thermal balance for the phase separation surface. We constructed numerical algorithmic models for calculations of temperature change of heat-accumulating material in time. Such calculations allowed determining the optimal number of U-shaped tubes based on which we proposed the heat accumulator design. We manufactured the heat accumulator, tested, and proved its efficiency and positive effect on the engine warm-up time and the passenger compartment.
\end{abstract}

\section{Introduction}

When the ambient temperatures are low during prolonged parking, for example, at night, there are difficulties with starting the engine at the beginning of operation (the so-called "cold start"). It takes a long time to warm up the engine, when the engine is idling, consuming a significant amount of fuel, discharging exhaust gases into the atmosphere [1], the car remains cold for a long time, creating discomfort for the driver and passengers.

Cold start is characterized by decreasing engine life, increasing specific fuel consumption (according to various sources by $7-20 \%$ ), the difficulty of ensuring the starting speed of the crankshaft, deteriorating of the conditions of mixture formation and flame formation of the air-fuel mixture. It is caused by decreasing temperature of motor oil, fuel, the storage battery, details of the engine and features of its starting properties.

In this regard, attention is paid to creating favorable conditions for starting the car engine in the cold season.

\section{Literature review}

One of the solutions that minimizes the negative effects of cold start is the pre-starting thermal preparation of the engine [1]. The specified preparation is realized by means of pre-starting heaters which depending on the principle of work are divided into electric $(220 \mathrm{~V}$ and $12 \mathrm{~V})$, independent, executed in the form of the separate gasoline or diesel module, and thermal accumulators which are devices for accumulation of the released parasitic heat, emitted during engine operation in the form of a heated fluid in the cooling circuit or thermal energy of the exhaust gases.

The problem of thermal energy accumulation through phase transformations is relevant today. This is evidenced by numerous publications in the world scientific literature. Recent works on this topic include using of accumulated energy in heat accumulators in such industries as construction [2-5], solar energy [6, 7], energy conservation [8-13] and others [14]. Research is being conducted on the types of heat-transfer accumulating materials and methods of their placement in the heat accumulator. As heat-transfer accumulating materials, either crystal hydrates of salts and bases or organic substances such as paraffins, waxes, etc. are used $[13,15,16]$. As for the placement of these materials in the heat accumulator, as one of the options proposed capsule heat transfer phase transition [17].

A number of works investigate increasing the heat transfer of phase-changing materials in order to increase the efficiency of heat accumulators $[12,13]$.

The studies of heat accumulators using in transport technology cover a wide range of issues. Recent developments include using of these devices for drying car bodies [18], for heating and cooling the working

\footnotetext{
* Corresponding author: kluevaaleksandra64@gmail.com
} 
fluid [19], specially designed heat accumulators for refrigeration [20], resolving the issues of the location of the heat accumulator in the engine system [21]. For all these cases the design of the heat accumulator and its location in motor transport is offered.

The most favorable solution for pre-warming up the car engine is using of a heat accumulator based on a solid-liquid phase transition (fusible heat-accumulating materials) [19]. In addition to the phase transition heat, the heat from the heating of the solid and liquid phase is used. The advantage of such designs is the high specific heat capacity, which determines their compactness. In addition, the constant temperature of discharging due to the phase transition provides greater efficiency compared to storage systems without a phase transition. Structurally, such heat accumulators can be made in the form of shell-and-tube heat exchangers, in the pipe space of which moves, for example, the liquid of the car cooling system (in our case - antifreeze), and in the intertube space there is a phase-transfer heat storage material (in our case - ozokerite). When designing such devices, it is necessary to model their operation in order to determine the optimal heat transfer surface, and from it - the number of structural elements, such as the tubes of the device.

\section{Research methodology}

We performed simulation of the heat accumulator working process for the pre-heating of the car engine by compiling the heat balance of a closed circulation system $[22,23]$.

We performed numerical calculations of the system engine - circulating fluid - heat storage material environment in two stages. The task was divided into stages to reduce the need for computing resources - a complete finite-volume model of the system requires significant computing power. In the first stage, we calculated the parameters of thermal and hydraulic resistances in the engine system and piping system for different temperatures of the coolant by the finite volume method in the CFD system (Fig. 1).

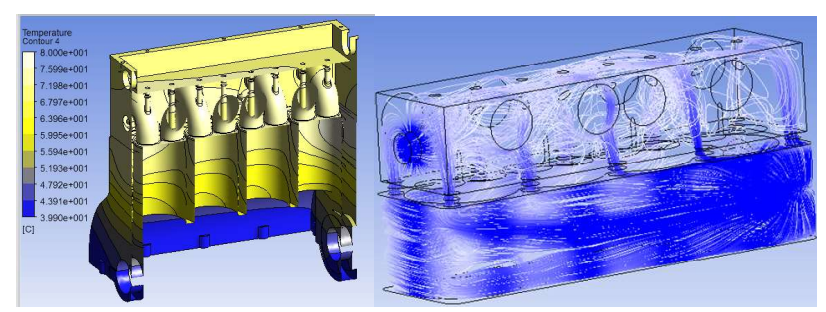

Fig. 1. Estimated CFD-picture of heating the surfaces of the engine (a) and the flow line in the channels (b).

In the second stage, the problem was solved numerically by the method of equivalent thermal circuits. The system of thermal equations for each section has the form:

$$
\begin{aligned}
& C_{1} \frac{d T_{1}}{d \tau}+\Lambda_{11}\left(T_{1}-T_{2}\right)+\Lambda_{12}\left(T_{1}-T_{3}\right)+\Lambda_{13}\left(T_{1}-T_{e}\right)=P_{1}, \\
& C_{2} \frac{d T_{2}}{d \tau}+\Lambda_{21}\left(T_{1}-T_{2}\right)+\Lambda_{22}\left(T_{1}-T_{3}\right)+\Lambda_{23}\left(T_{1}-T_{e}\right)=P_{2},
\end{aligned}
$$

or in matrix form:

$$
[C] \cdot \dot{\mathbf{T}}+[\Lambda] \cdot \mathbf{T}=\mathbf{P},
$$

where $[C]$ - the matrix of heat capacities (diagonal), $\mathbf{T}$ - the column of nodal temperatures, $T_{e}-$ the temperature of the environment, $[\Lambda]$ - the matrix of thermal conductivities, $\mathbf{P}-$ the power vector of the thermal source.

A separate issue is the modeling of the phase transition. As is known, on the basis of heat balance for the phase interface is usually used Stefan condition [24]:

$$
\rho_{s} q_{f} \frac{\partial s_{n}}{\partial \tau}=\left.\lambda_{l} \frac{\partial T}{\partial n}\right|_{n \rightarrow+0}-\left.\lambda_{s} \frac{\partial T}{\partial n}\right|_{n \rightarrow-0}
$$

where $s_{n}-$ the displacement of the phase boundary in the direction of the normal $n, \tau-$ time, $T-$ the temperature, $q_{f}$ - the heat of fusion, $\lambda_{l}$ та $\lambda_{s}$ - the thermal conductivity coefficients of the liquid and solid phases, respectively. In addition to this condition, most Stefanow-type problems use the condition of constant temperature at the interphase boundary.

In our case, it is desirable to model the melting process of the working fluid using the method of effective heat capacity without the available allocation of the position of the phase boundaries, taking into account the convective heat transfer in the melt:

$$
c_{e f f} \rho\left(\frac{\partial T}{\partial \tau}+\mathbf{v} \nabla T\right)=\nabla\left(\lambda_{e f f} \nabla T\right)+q
$$

where $c_{\text {eff }} \lambda_{\text {eff }}$ - effective values of heat capacity and thermal conductivity, which take into account the heat of fusion in the Stefan problem and the presence of convective heat transfer, $\mathbf{v}-$ velocity field (convective currents), $q$ - power of internal heat sources, if they belong. To take into account the phase transition, the effective heat capacity includes a delta function and it is represented as:

$$
c_{e f f}=c(T)+q_{n} \delta\left(T-T^{*}\right)
$$

where $T^{*}$ - the phase transition temperature.

In the numerical implementation in the finite temperature range $\Delta T$ for the phase transition point, the second term can be replaced by the expression $q_{n} / \Delta T$.

Some heat-accumulating substances are materials with strongly blurred boundaries of phase changes solid - liquid. In these cases, the temperature interval of phase changes can stretch by several degrees, so the temperature dependence of the specific thermal capacity $c=c(T)$, which in the phase transition zone has one or more peaks, and the phase transition region will not be a surface but a spherical solid. It is also possible the presence of supercooling during crystallization, which, for example, is characteristic of crystal hydrates without forming solid particles of additives, but in practice the 
account of the specified phenomenon, is carried out seldom.

From this perspective, the set of equations of thermal state for each section has the form:

$$
\begin{aligned}
& m_{1} c_{1} \frac{d T_{1}}{d t}=-k_{12}\left(T_{1}-T_{2}\right) F_{12}-k_{10}\left(T_{1}-T_{e}\right) F_{13}, \\
& m_{2} c_{2} \frac{d T_{2}}{d t}=-k_{12}\left(T_{2}-T_{1}\right) F_{12}-k_{20}\left(T_{2}-T_{e}\right) F_{20}-k_{23}\left(T_{2}-T_{3}\right) F_{23}, \\
& m_{3} c_{3} \frac{d T_{3}}{d t}=-k_{23}\left(T_{3}-T_{2}\right) F_{23}-k_{30}\left(T_{3}-T_{e}\right) F_{30},
\end{aligned}
$$

where $T_{1}, T_{2}, T_{3}$ - respectively the temperature (average of the volume in the system) of the heat-storing material, antifreeze and engine;

$m_{1}$ - the mass of heat storage material, $m_{2}-$ the mass of antifreeze involved in heat transfer (for different cycles may be different), $m_{3}$ - useful weight of the engine (involved in heat exchange);

$c_{1}, c_{2}, c_{3},-$ corresponding to the heat capacity, while $c_{l}$ is given by the method of effective heat capacity as a piecewise function in the form:

$-k_{12}\left(T_{1}-T_{2}\right) F_{12}$ - the heat flux from the material to the antifreeze (and the corresponding coefficient of heat transfer and area);

$-k_{10}\left(T_{1}-T_{e}\right) F_{10}-$ the heat flux from the material into the environment through the walls of the heat exchanger (and the corresponding heat transfer coefficient and area);

$-k_{20}\left(T_{2}-T_{e}\right) F_{20}$ - the heat flow from the material to the environment through the connecting pipes (and the corresponding heat transfer coefficient and area);

$$
-k_{23}\left(T_{2}-T_{3}\right) F_{23}-\text { the heat flow from the }
$$
antifreeze to the engine (and the corresponding heat transfer coefficient and area);

$-k_{30}\left(T_{3}-T_{e}\right) F_{30}-$ the heat flow from the engine to the environment through its surface.

Initial conditions $T_{1}$ - the temperature of the heataccumulating material after down time, $T_{2}-$ the initial temperature of antifreeze (calculated as the average between the engine and the material, but arbitrary choice is proportional to the ratio of volumes in the engine and heat exchanger), $T_{3}$ - the initial engine temperature (take as ambient temperature).

\section{Results}

We used numerical calculations of system engine circulating fluid - heat storage material - environment in the development of the design of the heat accumulator with the heat-accumulating material of the phase transition. Ozokerite was used as the heat storage material (HSM) and liquid of the engine cooling system - antifreeze as a heat carrier. The heat accumulator is a heat exchanger in which the antifreeze moves through U-shaped tubes, and in the intertube space is ozokerite. We proposed this design based on the analysis of different types of heat accumulators, heat storage substances and heat carriers.
When designing a heat accumulator it is necessary to solve the question of the size of the heat transfer surface between HSM and antifreeze, which is provided by the tubes of the U-shaped liquid heat exchanger. In this regard, we conducted a numerical solution of the system (4) for the engine model with heat accumulator (HA) on

\begin{tabular}{|c|c|c|}
\hline $\begin{array}{l}\text { Parameter } \\
\text { groups }\end{array}$ & Name of elements & $\begin{array}{l}\text { Numerical } \\
\text { value }\end{array}$ \\
\hline \multirow[t]{3}{*}{$\begin{array}{l}\text { Tube } \\
\text { parameters }\end{array}$} & $\begin{array}{l}\text { Number of U-shaped } \\
\text { tubes }\end{array}$ & $1,3,6$ \\
\hline & Diameter of tubes, $m$ & 0,015 \\
\hline & $\begin{array}{l}\text { Estimated total length } \\
\text { of the U-shaped tube, } \\
\mathrm{m}\end{array}$ & 1,1 \\
\hline \multirow{3}{*}{$\begin{array}{l}\text { Heat } \\
\text { accumulator } \\
\text { parameters }\end{array}$} & Length of HA, m & 0,6 \\
\hline & Diameter of HA, m & 0,1 \\
\hline & $\begin{array}{l}\text { The area of the casing } \\
\text { of the heat } \\
\text { accumulator, } \mathrm{m}^{2}\end{array}$ & 0,2041 \\
\hline \multirow[t]{5}{*}{$\begin{array}{l}\text { Volumes and } \\
\text { masses of HAM } \\
\text { and coolant }\end{array}$} & $\begin{array}{l}\text { Base volume of HAM } \\
\text { (adjustable depending } \\
\text { on the number of } \\
\text { tubes), } \mathrm{m}^{3}\end{array}$ & 0,004127 \\
\hline & $\begin{array}{l}\text { Base weight HAM } \\
\text { (adjusted depending } \\
\text { on the number of } \\
\text { tubes), kg }\end{array}$ & 4,1227 \\
\hline & $\begin{array}{l}\text { Base volume of } \\
\text { antifreeze in HA } \\
\text { tubes (adjusted } \\
\text { depending on the } \\
\text { number of tubes), } \mathrm{m}^{3}\end{array}$ & 0,0005829 \\
\hline & $\begin{array}{l}\text { Volume of circulating } \\
\text { liquid, } \mathrm{m}^{3}\end{array}$ & $11 \cdot 10^{-3}$ \\
\hline & $\begin{array}{l}\text { Mass of circulating } \\
\text { liquid, } \mathrm{kg}\end{array}$ & 11 \\
\hline \multirow{2}{*}{$\begin{array}{l}\text { Physical } \\
\text { properties of } \\
\text { materials }\end{array}$} & $\begin{array}{l}\text { Density of HAM, } \\
\mathrm{kg} / \mathrm{m}^{3}\end{array}$ & 2000 \\
\hline & $\begin{array}{l}\text { Density of circulating } \\
\text { liquid, } \mathrm{kg} / \mathrm{m}^{3}\end{array}$ & 1000 \\
\hline \multirow[t]{5}{*}{$\begin{array}{l}\text { Thermophysical } \\
\text { characteristics } \\
\text { of } \\
\text { HAM and } \\
\text { engine coolant }\end{array}$} & $\begin{array}{l}\text { Heat capacity of } \\
\text { HAM beyond phase } \\
\text { transition, } \mathrm{J} /(\mathrm{kg} \cdot \mathrm{K})\end{array}$ & $\begin{array}{c}3600 \\
\text { (solid } \\
\text { phase) } \\
3340 \\
\text { (liquid) } \\
\end{array}$ \\
\hline & $\begin{array}{l}\text { Heat transfer from the } \\
\text { material during } \\
\text { natural convection } \\
(\text { standstill }), \mathrm{W} /\left(\mathrm{m}^{2} \cdot \mathrm{K}\right)\end{array}$ & 1000 \\
\hline & $\begin{array}{l}\text { Heat capacity of } \\
\text { circulating fluid, } \mathrm{J} / \\
(\mathrm{kg} \cdot \mathrm{K})\end{array}$ & 3000 \\
\hline & $\begin{array}{l}\text { Heat of phase } \\
\text { transition, } \mathrm{J} / \mathrm{kg}\end{array}$ & $140 \cdot 10^{3}$ \\
\hline & $\begin{array}{l}\text { Heat transfer } \\
\text { coefficient through }\end{array}$ & 0,74 \\
\hline
\end{tabular}
one, three and six tubes. The calculations were performed under the conditions specified in table 1.

Table 1. Model's parameters. 


\begin{tabular}{|l|l|c|}
\hline \multirow{5}{*}{} & $\begin{array}{l}\text { insulation, } \\
\mathrm{W} /\left(\mathrm{m}^{2} \cdot \mathrm{K}\right)\end{array}$ & \multirow{2}{*}{} \\
\cline { 2 - 3 } & $\begin{array}{l}\text { Heat transfer } \\
\text { coefficient to the } \\
\text { environment, } \\
\mathrm{W} /\left(\mathrm{m}^{2} \cdot \mathrm{K}\right)\end{array}$ & 10 \\
\cline { 2 - 3 } & $\begin{array}{l}\text { Phase transition } \\
\text { temperature of heat } \\
\text { storage material, }{ }^{\circ} \mathrm{C}\end{array}$ & 70 \\
\hline \multirow{5}{*}{$\begin{array}{l}\text { Engine } \\
\text { parameters }\end{array}$} & $\begin{array}{l}\text { The volume of } \\
\text { circulating fluid in the } \\
\text { engine, } 1\end{array}$ & 28 \\
\hline & $\begin{array}{l}\text { Engine surface area } \\
\text { (external), } \mathrm{m}^{2}\end{array}$ & 2,7 \\
\cline { 2 - 3 } & $\begin{array}{l}\text { Engine surface area } \\
\text { (internal), } \mathrm{m}^{2}\end{array}$ & 2,2 \\
\cline { 2 - 3 } & $\begin{array}{l}\text { Engine weight } \\
\text { (involved in heat } \\
\text { transfer), kg }\end{array}$ & 250 \\
\cline { 2 - 3 } & $\begin{array}{l}\text { The average heat } \\
\text { capacity of the } \\
\text { engine, } \mathrm{J} /(\mathrm{kg} \cdot \mathrm{K})\end{array}$ & 550 \\
\hline $\begin{array}{l}\text { Additional } \\
\text { parameters }\end{array}$ & $\begin{array}{l}\text { The thickness of the } \\
\text { insulation layer } \\
\text { (foam), mm }\end{array}$ & 50 \\
\cline { 2 - 3 } & $\begin{array}{l}\text { Ambient temperature, } \\
{ }^{\circ} \mathrm{C}\end{array}$ & -10 \\
\hline
\end{tabular}

We performed the calculation in the Maple environment according to the following finitedifference scheme:

$$
\begin{aligned}
T_{1, i+1}= & T_{1, i}-\frac{1}{m_{1} c_{1}}\left[k_{12}\left(T_{1, i}-T_{2, i}\right) F_{12}+k_{10}\left(T_{1, i}-T_{e_{i}}\right) F_{13}\right] \Delta t, \\
T_{2, i+1}= & T_{2, i}-\frac{1}{m_{2} c_{2}}\left[k_{12}\left(T_{2, i}-T_{1, i}\right) F_{12}+k_{20}\left(T_{2, i}-T_{e i}\right) F_{20}+\right. \\
& \left.+k_{23}\left(T_{2, i}-T_{3, i}\right) F_{23} \Delta t\right], \\
T_{3, i+1}= & T_{3, i}-\frac{1}{m_{3} c_{3}}\left[k_{23}\left(T_{3, i}-T_{2, i}\right) F_{23}+k_{30}\left(T_{3, i}-T_{e_{i}}\right) F_{30}\right] \Delta t,
\end{aligned}
$$

where $i$ - the iteration index when splitting by time.

In fig. 2 presents the results of solving the system of equations (4) for the model engine - heat accumulator - circulation system using different design solutions of HA.

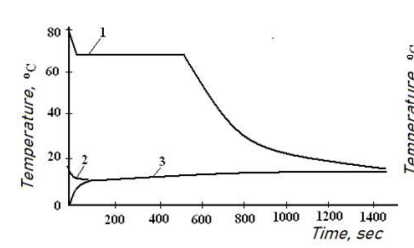

a)

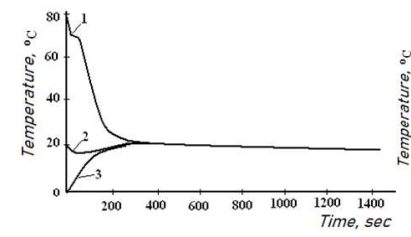

c)

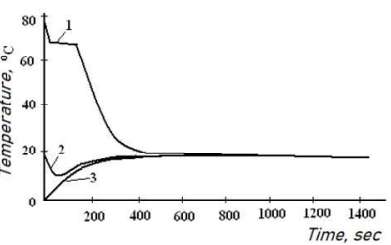

b)

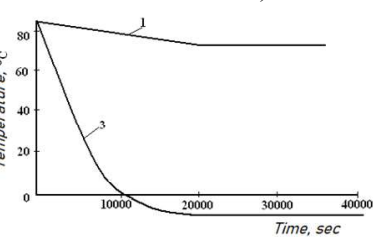

d)
Fig. 2. The process of discharging HA with engine cooling depending on the number of U-shaped tubes in the liquid heat exchanger: a) - one tube; b) - three tubes; c) - six tubes; d) schedule of HA cooling compared to the internal combustion engine at idle. 1 - discharge of heat accumulating substance, 2 - warming up of cooling liquid, 3 - warming up of the engine.

Calculations give us a picture of HAM cooling. From the point of view of efficiency of the heat accumulator work its discharge time (engine heating) should be the smallest. When using one U-shaped tube, the mass of HAM in the intertube space of HAM is the largest, cooling is slower. Increasing the number of Ushaped tubes leads to a decrease in the mass of HAM (and, as a consequence, the possibility of heat accumulation), and (for a small number of tubes) a reduction in the discharge time.

According to the results of calculations, we see that in terms of heating efficiency and efficiency in terms of metal consumption the most advantageous solution is the design of a heat storage with three tubes.

The scheme of the heat accumulator for pre-starting warming up of the car engine is presented on fig. 3 .

The heat accumulator represents two coaxial cylindrical vessels. The inner tank is a shell-and-tube heat exchanger with three U-shaped tubes through which the antifreeze moves, and the intertube space is filled with heat-accumulating material. The gap between the two cylinders contains a heat-insulating liquid (for example, water or antifreeze), to the same place is builtin the tubular heating element (THE).

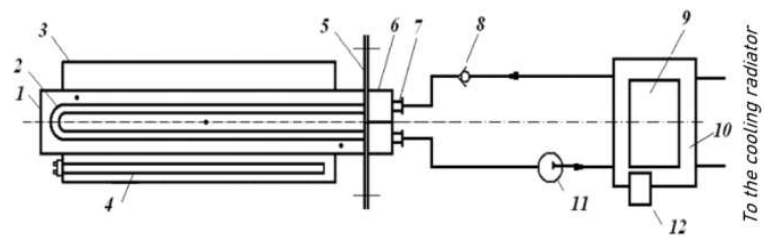

Fig. 3. The experimental sample of the phase transition heat accumulator:

1 - cylindrical tank filled with ozokerite; 2 - U-shaped tube for antifreeze, which circulates in the circuit of HA-cooling system of the engine (the number of tubes may be different); 3 - container filled with insulating liquid; 4 - THE; 5 installation grate; 6 - cover; 7 - pipes for input and output of antifreeze; 8 - solenoid valves; 9 - engine; 10 - engine cooling shell; 11 - the pump of system of HA, 12 - the pump of system of cooling of the engine. Dots mark places of temperature measurement of HAM.

The heat accumulator works like this. When the car moves, the heat accumulator is charged with a thermal charge carrier - hot engine cooling liquid (antifreeze), which circulates by means of a pump of the engine cooling system in a closed circuit through antifreeze inlet and outlet pipes, collector chamber, U-shaped liquid tube. Passing through the U-shaped liquid heat exchanger, the antifreeze heats the phase-transfer heataccumulating material and maintains it in a molten and heated to a temperature of $95-102^{\circ} \mathrm{C}$ state. When the car stops, the heat accumulator is disconnected from the engine cooling system by means of a solenoid valve. During the down time car period, the heat-accumulating material and the engine cooling liquid (antifreeze) are cooled, the heat-accumulating material crystallizes, due 
to which heat is released, which maintains the antifreeze temperature at $40-45^{\circ} \mathrm{C}$ for 12 hours to one day depending on thermal insulation of the heat accumulator. To operate the heat accumulator in order to preheat the engine turn on the pump, organizing the circulation of the heat carrier - cold engine coolant (antifreeze), in the above closed circuit with a U-shaped liquid heat exchanger, which heats the coolant to the engine. When the car stands for a long time, the THE is switched on, which heats the thermal liquid insulation in the gap of the double sealed housing up to $80^{\circ} \mathrm{C}$. This is sufficient to melt the phase-transfer heat-accumulating material and to preheat the internal combustion engine using the above-mentioned closed circuit with a Ushaped liquid heat exchanger. When starting the internal combustion engine with the help of the engine cooling system pump, the engine coolant is circulated along the above-mentioned circuit with a U-shaped liquid heat exchanger - the heat accumulator is charged.

\section{Conclusions}

Modeling with the division of the problem into stages can be used in the design and manufacture of the heat accumulator of the car engine pre-heating system. The CFD-modeling stage allows determining the thermal and hydraulic resistances of the system, the stage of equivalent thermal circuits allows to predict the behavior of the system engine - heat accumulator circulation system as a whole. The manufacture of such a heat accumulator and its subsequent testing proved its efficiency and a positive effect on the warm-up time of the car. Thus, the use of modern modeling methods allows determining the dimensions of the heat accumulator and predicting the operation of the system in different conditions.

\section{References}

1. D. Appel, F. Hagen, U. Wagner, T. Koch, H. Bockhorn, D.Trimis, Influence of low ambient temperatures on the exhaust gas and deposit composition of gasoline engines, in Internal Combustion Engine Division Fall Technical Conference, 4-6 November 2020, Online, 1-11 (2020)

2. M. Kenisarin, K. Mahkamov, Passive thermal control in residential buildings using phase change materials, Renew. Sustain. Energy Rev. 55, 371-398 (2016)

3. I. Sarbu, C. Sebarchievici, A comprehensive review of thermal energy storage, Sustainability. 10, 1-33 (2018)

4. I. Sarbu, A. Dorca, Review on heat transfer analysis in thermal energy storage using latent heat storage systems and phase change materials, Int. J. Energy Res. 43, 29-64 (2019)

5. C. Zengab, X. Caoa, F. Haghighatb, Y. Yuana, L. Klimesc, Buried water-phase change material storage for load shifting: A parametric study, Energy Build.

227, 15 (2020)

6. M. Savytskyi, V. Danishevskyy, M. Bordun, Accumulation of solar energy to heat greenhouses, Mater. Sci. Eng. 985, 8 (2020)

7. J. Jiang, Z. Chen, L. Bo, H. Cui, P. Peng, Study on heat transfer enhancement of solar finned tube phase change regenerator, Environ. Earth Sci. 615, 5 (2020)

8. L. Henríquez-Vargas, A. Reyes, M. Quiroga, F. Angel, N. Pailahueque, P. Donoso-García, Thermoelectric generation in a PCM-based energy accumulator, Int. J. Heat Mass Transf. 57, 12651274 (2021)

9. V.E. Yurin, M.A. Murtazov, Efficiency investigation of nuclear power plant combination with a system of water and phase-transfer heat accumulators, J. Phys. 1652, 7 (2020)

10. H. Zhang, J. Baeyens, G. Caceres, J. Degreve, Thermal energy storage: recent developments and practical aspects, Prog. Energy Combust. Sci. 53, 1-40 (2016)

11. J. Pereira da Cunha, P. Eames, Thermal energy storage for low and medium temperature applications using phase change materials-a review, Appl. Energy, 177, 227-238 (2016)

12. N.I. Ibrahim, F.A. Al-Sulaiman, S. Rahman, B.S.Yilbas, A.Z. Sahin, Heat transfer enhancement of phase change materials for thermal energy storage applications: a critical review, Renew. Sustain. Energy Rev. 74, 26-50 (2017)

13. J.M. Mahdi, S. Lohrasbi, D.D. Ganji, E.C. Nsofor, Accelerated melting of PCM in energy storage systems via novel configuration of fins in the triplex tube heat exchanger, Int. J. Heat Mass Transf. 124, 663-676 (2018)

14. S. Sama, T. Badamo, P. Lynch, G. Manogharan, Novel sprue designs in metal casting via $3 D$ sandprinting, Addit Manuf. 25, 563 (2019)

15. G. Wang, M. Danneman, C. Xua, G. Englmair, S. Furbo, J. Fan, Thermal characteristics of a longterm heat storage unit with sodium acetate trihydrate, Appl. Therm. Eng. 187, 25 (2021)

16. J. Dong, L. Zhang, Y. Jiangab, A comparative study on system performances of multi-split air source heat pump with different energy accumulators and storage methods, Energy Build. 231, 15 (2021)

17. L. Solomon, Y. Zheng, K. Tuzla, S. Neti, A. Oztekin, Analysis of an encapsulated phase change material based energy storage system for high temperature applications, Int. J. Energy Res. 42, 2518-2535 (2018)

18. J. Weschke, D. Wieland, J. Jost, Drying system comprising a thermal engine, patent, IN6282DEN2012A (2015)

19. W. Ruck, O. Opel, U. Leuphana, Method, heat accumulator and heat accumulator system for heating and cooling a working fluid, patent, US2013167534A1 (2013) 
20. P. Houdek, V. Rajtmajer, M. Kolda, M. Kopecka, M. Hegar, Thermal accumulator for a transport refrigeration system, patent, WO2015168569A1 (2015)

21. A. Eilemann, S. Ignjatovic, R. Koelblin, Heat accumulator, patent, US10138798B2 (2018)

22. M. S. Purdin, Numerical modelling method of heat exchange in heat accumulators with many phases and free phase boundaries movement, J. Phys. 1683, 7 (2020)

23. M. Rimár, A. Kulikov, M. Fedak, M. Abraham, CFD analysis of the ventilation heating system, Mech. Ind. 20, 708 (2019)

24. J. Stefan, Some historical notes about the Stefan problem, Ann. Phys. Chem. 278, 965 (1891) 